\title{
THE CLIMATE CHANGE POLICY \\ FRAMEWORK AND ALLIED PROGRAMS IN INDIA
}

\author{
Rameshwar Sorokhaibam, Shikha Vardhan and \\ Aakash Shrivastava
}

\section{Introduction}

Climate change has become a reality and is widely considered to be one of the biggest threats to humankind today. To address this threat, international cooperation is essential; all nations need to contribute to the global effort in order to significantly mitigate the effects of climate change. This chapter will provide

1. A brief overview of the initiatives and policy frameworks to address the threat of climate change both at the global and national levels.

2. An outline of the strategies proposed under India's National Program on Climate Change and Human Health (NPCCHH).

3. An exploration of areas for coordination and cooperation with allied programmes related to climate change and health.

\section{Climate change initiatives and policy frameworks at the global and national level}

The Inter-governmental Panel on Climate Change (IPCC), an international body created in 1988 for the purpose of assessing climate change, released its first scientific assessment report in 1990 (FAR, 1990). The report underlined the importance of international cooperation to tackle climate change and its consequences, and played a role in the creation of the United Nations Framework Convention on Climate Change (UNFCCC). The UNFCCC was adopted in 1992 and came into force on 21 March 1994 after receiving its fiftieth ratification. There are currently 197 Parties to the Convention, of which India is a part (UNFCCC, 2021). The UNFCCC is the parent treaty to the 2015 Paris Agreement and the 1997 Kyoto Protocol in which the Parties to the Convention have determined their obligations on Nationally Determined Contributions (NDCs) to limit their carbon footprint in the coming years (UNFCCC, 2020). 
Its long-term objective is 'to stabilise atmospheric greenhouse gas concentrations at a level that would prevent dangerous anthropogenic interference with the climate system in a time frame which allows ecosystems to adapt naturally and enable sustainable development.' In relation to climate change and health, there is an operational framework developed for climateresilient health systems under the World Health Organization (WHO), whose purpose is to provide guidance to health systems and public health programming on how to increase their capacity for protecting health in an unstable and changing climate.

To fulfil India's commitment to the UNFCCC (Article 12), an Initial National Communication was formed in 2004 (UNFCCC, 2004), leading to the formation of the high-level Prime Minister's Council on Climate Change (PMCCC) on 5 June 2007 (PMO Archives, 2007). India's Climate Change policy comes under the PMCCC to address issues arising from climate change in the diverse geo-climatic regions in the country. The policy advises on proactive measures to be taken, and facilitates inter-ministerial coordination and guides for the assessment, adaptation and mitigation of climate change in the country. The policy is reflected in the National Action Plan on Climate Change (NAPCC) of the Ministry of Environment, Forest and Climate Change (MoEFCC) that was released in 2008 (Pandve, 2009). India's Intended Nationally Determined Commitments (INDC) were submitted to the UNFCCC in 2015.

The NAPCC initially enshrined eight national missions (Solar Energy, Enhanced Energy Efficiency, Sustainable Habitat, Water, Sustaining the Himalayan Eco-system, Green India, Sustainable Agriculture and Strategic Knowledge for Climate Change) that represent multipronged, long-term and integrated strategies for achieving key goals in the context of climate change in the country. The PMCCC was reconstituted in 2015 and reviewed progress of the eight national missions proposed under the NAPCC of MoEFCC. Since health consequences were not addressed in any of the eight missions, the PMCCC proposed to expand missions under NAPCC and suggested four new missions, of which one was Health. Although MoEFCC is the overall nodal ministry for climate change in the country, the Ministry of Health and Family Welfare (MoHFW) is the nodal Ministry for the Health Mission on Climate Change. See Figure 4.1 for the global, national, state and district level bodies for climate change action in the health sector.

\section{National Program on Climate Change and Human Health}

Under the MoHFW, the National Centre for Disease Control (NCDC), New Delhi, is designated as a technical nodal agency for implementing the Health Mission on Climate Change in the country. The NCDC drafted the National Action Plan for Climate Change and Human Health (NAPCCHH) in 2018; this was approved by the MoHFW in February 2019. The action plan lays 


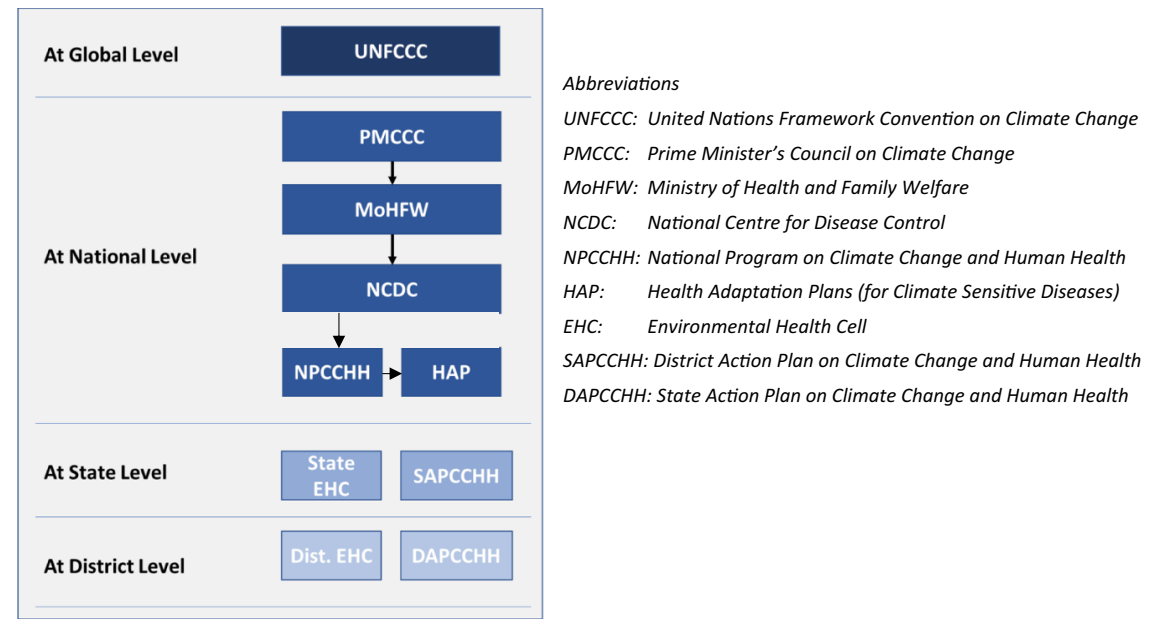

Figure 4.1 Climate change action in the health sector at global and national levels.

out the guiding principles for the national programme - National Programme on Climate Change and Human Health (NPCCHH - Table 4.1), which comes under the National Health Mission. The plan provides a detailed layout of the adaptation plans on health effects due to climate change.

Table 4.1 The vision, goal and objectives of NPCCHH

A climate-smart and-resilient health system that promotes health
and protects against climate risks among all citizens of India,
especially those who are vulnerable including children, women
and marginalised populations.
To strengthen healthcare services against the adverse impact of
extreme weathers, climate variability and change.
To strengthen healthcare services against the adverse impact of
climate change on health. The specific objectives are
1. To create awareness among the general population (vulnerable
communities), healthcare providers and policymakers regarding
impacts of climate change on human health
2. To build and strengthen the capacity of health systems to
address illnesses due to impacts of climate change on human
health
3. To strengthen health preparedness and responses to climate-
sensitive health risks
4. To develop partnerships and create synchrony and synergy with
other national missions on Climate Change for adequate
representation of health
5. To strengthen research capacity to fill evidence gaps on the
impact of climate change on human health


Under the NPCCHH, the following have been identified as Climate Sensitive Diseases (CSDs):

- Water-borne diseases

- Vector-borne diseases

- Air pollution-related illnesses

- Allergic disorders

- Cardiovascular diseases

- Nutrition-related illnesses

- Coastal climate-sensitive diseases

- CSDs in hilly and mountainous regions

- Occupational health

- Mental health

- Disaster-related illnesses

- Zoonotic diseases

- Heat stress and heat-related illnesses

With regard to the CSDs, Centres of Excellence (CoE) have been identified from across the country to play an important role to help NCDC develop specific health adaptation plans, training modules, guidelines, SOPs, etc., and to support State programme officers on climate change in developing disease-specific adaptation plans in the States. The case studies in boxes discuss NPCCHH programmes that address heat-related illnesses (Box 4.1) and air pollution-related illnesses in the country (Box 4.2), with Table 4.2 displaying the key strategies issued by NPCCHH for heat-related illnesses.

\section{Box 4.1 Case study}

\section{Addressing heat-related illnesses under the NPCCHH}

Under the MoHFW, the NPCCHH programme tracks the health effects due to heat in the country and has prepared guidelines on the prevention and management of heat-related illnesses. The public health actions required for managing heat-related illnesses are surveillance of heat-related illnesses morbidity and mortality, investigation of heat-related health events, pre-hospital and hospital care, logistics, training of doctors and nurses, awareness among the general public, coordination with multiple stakeholders, heat action plans for specific cities/rural districts, particularly for vulnerable population groups, and roping in of Non-Government Organizations (NGOs) for spreading awareness on heat-related illnesses. Since 2015, the Integrated Disease Surveillance Program (IDSP) under the MoHFW 
has collected and compiled data of heat-related illnesses from 17 vulnerable States: Andhra Pradesh, Bihar, Chhattisgarh, Delhi, Gujarat, Haryana, Jharkhand, Karnataka, Maharashtra, Madhya Pradesh, Odisha, Punjab, Rajasthan, Tamil Nadu, Telangana, Uttar Pradesh and West Bengal. In 2019, the vulnerable States increased to 23 in number, including Kerala, Goa, Uttarakhand, Jammu \& Kashmir, Arunachal Pradesh and Himachal Pradesh. Currently, information on morbidity and mortality of heat-related illnesses is being captured on a daily basis at the health facility level; this information is being compiled for all districts and from there to the states, and then further to the national level.

\section{Box 4.2 Case study \\ Addressing air pollution and its health impacts under the NPCCHH}

Due to the health impacts of air pollution, the MoHFW started a programme for Acute Respiratory Illnesses (ARI) surveillance in 2017 in six Central Government tertiary care hospitals in Delhi. The ARI data is being correlated with the daily air quality level, i.e. air quality index (AQI) of the respective area or city. The overarching goal of ARI surveillance is to minimise the impact of air pollution by providing useful information to public health authorities for the appropriate control and intervention measures, health resource allocation, and to make case management recommendations. Some action plans for air pollution-related health impacts are listed below:

1. All cities enlisted under the National Clean Air Program are selected with 2 to 4 tertiary hospitals for ARI surveillance in its first phase.

2. Capacity-building of health professionals on the health effects of air pollution is being conducted.

3. Information Education Communication (IEC) materials have been prepared for print media and social media and shared with the States to prepare and adopt protective measures on health effects due to air pollution; social media campaigns are running on the MoHFW and NCDC social media sites.

4. State/District/City Level Health Sector Adaptation Plans for Air Pollution and Health are being developed to ensure preparedness and coordination whenever air pollution arises, 
along with evaluation at regular intervals. The action plan will help in prioritising the most affected areas, vulnerable groups and resource allocations, and identifying and defining the roles and responsibilities of the stakeholders through operational flowcharts or tables.

5. Research topics related to air pollution have been proposed and shared with the Indian Council for Medical Research (ICMR), an example being interventions in the form of face masks and room air purifiers to protect health from air pollution.

Table 4.2 Key strategies to adapt to heat-related illnesses in India

1. Strengthening Heat and Human Health Surveillance Systems with feedback received on reporting formats from various stakeholders at States, institutes and experts working on heat-related illnesses.

2. Standardising investigation of deaths due to suspected heatstroke cases: at the state/district level the suspect heat-related death is investigated by a team of tehsildar, revenue officer, police officer and medical officer.

3. Developing climate-specific state/district/city-specific Heat and Health Action Plans due to diverse geographies for heat vulnerable areas, vulnerable populations, health infrastructures and resources, and stakeholder identification with defined roles and responsibilities. The action plan will help in preparedness before season, response coordination during season and evaluation after season. This will be also incorporated into state/district/city level heat action plans developed by revenue/disaster management teams.

4. Increasing public awareness and community outreach to disseminate messages on how to prevent extreme heat events. Efforts include the use of social media such as SMS, radio, WhatsApp, email, social media, caller tunes, etc., particularly to reach the vulnerable populations.

5. Developing measures for Early Warning System/Alerts and responses at the state, district and below the district level. As IMD shares a daily five-day forecast on its website, a formal communication channel is being strengthened to alert health agencies for early response.

6. Capacity-building with the help of training modules among all levels of healthcare professionals to recognise and respond to heat-related illnesses.

\section{Addressing health impacts of climate change at the state and district level in India}

India is a country with diverse geo-climatic conditions impacting the health of the people due to climate change. Thus, the programme envisages that every State develops a State-specific Action Plan on Climate Change and Human Health (SAPCCHH) and District Action Plan on Climate Change and Human Health (DAPCCHH) at the district level. Each state has created an Environmental Health Cell at the state and district level, supervised by a 
designated state/district nodal officer for climate change and human health with supporting officers and staff. The nodal officer will coordinate with the Centre, State and District officers to achieve the objectives of the programme. The state action plan should be based on the previous years' statistics and information on the burden of prevalent CSDs, distribution of vulnerable populations, health infrastructure and other available resources, roles of various healthcare professionals, and other inter-coordinating stakeholders. The District Action Plan on Climate Change and Human Health (DAPCCHH) will enable adaptation of the health effects at the district level, taking it up to even the most remote healthcare facilities in the country.

\section{The provision of green and climate-resilient healthcare facilities under the NPCCHH}

Extreme weather events are increasing in frequency and magnitude. These events lead to disasters that cause direct health impacts. The National Disaster Management Authority (NDMA) is the nodal agency in the country to track disaster events occurring in the country, along with the State and District level disaster authorities. The NDMA has developed various policies and guidelines to deal proactively with these disasters, including disaster risk reduction for the major types of disasters. In the health sector, the NPCCHH programme requires support and collaboration with the NDMA as it has to deal with the direct health impacts of climate change which affect almost every part of the country. This programme incorporates the concepts of Green and Climate Resilient healthcare principles in revising the Indian Public Health Service Guidelines, which deal with SubCentres, PHCs, CHCs, SDHs and District Hospitals in the country. Green healthcare facilities will help to minimise the carbon footprint while climateresilient facilities will help adapt to the increasing frequency and magnitude of extreme weather events due to climate change. These extreme events can impact healthcare facilities and can collapse or paralyze their normal functioning leading to injuries, deaths and psychological impacts. There is a plan to either retrofit or develop climate-resilient healthcare facilities in various geo-climatic regions in the country affected by increasing extreme weather events due to climate change like heavy precipitations, floods, cyclones, heatwaves, and extreme colds, etc., in the country. This topic is discussed further in the chapter titled Green and Resilient Health Infrastructure.

\section{Awareness and capacity building of health professionals under the NPCCHH}

One of the main objectives of the programme is to bring about awareness and capacity building of health professionals. Various medical and allied councils have been sensitised for the inclusion of health impacts of climate 
change, air pollution and heat and their adaptation plans in Medical, Dental, Nursing and AYUSH curricula. Six Councils, i.e. the Medical Council of India, the National Board of Examinations, the Dental Council of India, the Nursing Council of India, the Central Council of Homoeopathy and the Central Council of Indian Medicine have accepted the proposal of its inclusion and have set up committees for consideration, processing and approval. A related component under the programme is developing training materials and modules for health professionals on climate change and health including medical officers, nursing officers and community health workers such as ASHA workers, etc. Some states are conducting awareness and capacity building for their health professionals. Training materials and modules are also being developed with consultations from various stakeholders including NGOs. Training on acute respiratory surveillance due to air pollution was recently conducted for medical officers of the state of UP at NCDC with support from UNEP and WHO recently. An awareness programme was conducted for district nodal officers in the state of Madhya Pradesh in Bhopal in January 2020.

\section{Other allied programmes in the health sector in India}

The NPCCHH requires full support from other related Missions on Climate Change under PMCCC, various other Ministries and Departments, public health institutions in the Government as well as private sectors and other international and national NGOs in developing a climate-resilient health sector in the country. Inter-sectoral and intra-sectoral co-ordinations among these institutes will be vital in achieving the objectives of the programme. Various public health institutions in autonomous institutions are taking on crucial roles in addressing the health impacts of climate change for further strengthening of the policy on Climate Change and Human Health, by providing input to the Government and contributing in capacity building. IGNOU has launched a post graduate certificate course in climate change. Reputed public health institutions in various private sectors in the country are also starting courses related to climate change in the health sector for capacity building and policy inputs on the subject.

There exist some limitations in the implementation of these activities and objectives mentioned under the programme in various States and Union Territories in the country. Climate change is a global phenomenon that impacts every part of the country, although to variable degrees. The programme has just started being newly implemented and requires support and expertise from across the health and non-health sectors in order to achieve its objectives. This requires huge inter-sectoral and intra-sectoral coordination, collaboration and cooperation. It requires a robust comprehensive approach with stronger leadership, policies, financing, capacity building of skilled and trained health professionals and workers, developing early warning mechanisms for climate-sensitive diseases and awareness generation at 
every level. The programme needs to be integrated with other health and non-health sector programmes horizontally, vertically and diagonally so that the adverse impacts of climate change on human health can be dealt with holistically. These are the huge challenges the programme needs to overcome in order to move forward positively and strongly.

\section{Key takeaways}

- Globally, the threat of climate change is being addressed by the IPCC and the UNFCCC, a Convention to which India is a signatory.

- National mechanisms to address Climate Change are the Prime Minister's Council on Climate Change and NAPCC from MoEFCC.

- The Health Mission on Climate Change (in India) was added to India's policy on Climate Change after a review of the NAPCC in the reconstituted PMCCC.

- The National Program on Climate Change and Human Health (NPCCHH) under the nodal Ministry of Health and Family Welfare and nodal technical agency National Centre for Disease Control, was started in order to fulfil India's commitments in the international and national climate change policy framework and to build a climateresilient health sector.

- The state and district-level climate activities and centres are described.

\section{References}

PMO Archives. (2007). PM's council on climate change constituted. https://archivepmo.nic.in/drmanmohansingh/press-details.php? nodeid $=575$

FAR. (1990). https://www.ipcc.ch/reports/

Pandve. (2009). India's national action plan on climate change. Indian Journal of Occupational and Environmental Medicine, 13(1), 17-19. doi: 10.4103/00195278.50718

UNFCCC. (2004). India's initial national communication to the UNFCCC. https:// unfccc.int/resource/docs/natc/indnc1.pdf

UNFCCC. (2020). UN climate change secretariat has new organizational structure. https:/unfccc.int/news/un-climate-change-secretariat-has-new-organizationalstructure

UNFCCC. (2021). Status of ratification of the convention. https://unfccc.int/processand-meetings/the-convention/status-of-ratification/status-of-ratification-ofthe-convention 